\title{
Semantic Web Application in Learning Resource Ontology Repository
}

\author{
Lasmedi Afuan \\ Departement of Computer Science, UGM \\ Yogyakarta \\ Indonesia
}

\author{
Azhari S.N. \\ Departement of Computer Science, UGM \\ Yogyakarta \\ Indonesia
}

\begin{abstract}
This research aims to implement the semantic web learning resource domain. Application of semantic web by utilizing RAP library is a RDF Api, SPARQL as a query to access $\mathrm{RDF}$, and PHP as server side scripting language. Steps being taken in this research include analysis of system requirements, data collection, design, coding, testing. The results of this research is a semantic web that helps in the search for learning resource.
\end{abstract}

\section{General Terms}

Semantic web, ontology, semantic search.

\section{Keywords}

Semantic web, ontology, learning resource, rdf api, sparql.

\section{INTRODUCTION}

Information technology has developed very rapidly, one of which is the development of internet technology. On the internet, a very popular service at this time is a web (WWW). Web a source of data is very large and very valuable to each user because in the interconnected web document and can be accessed through an internet connection [1]. The semantic web is a part of Web technologies that exist today, in the presence of the semantic web, the website is not only understandable by humans, but also can be understood by machines (machine readable). The semantic web is able to understand the meaning of a word or concept and be able to understand the logical connections between them. So the semantic web only the information required by the user.

Online learning (e-learning) to change the existing way of learning. E-learning with the learning process does not need to be done through face to face, learners (learners) can learn anywhere and anytime. In e-learning, content is one of the components of e-learning that is distributed with style semi tersruktur [2]. The problems that arise in e-learning content is search, often the search results display only the content based on keywords entered by learners. This research will develop a semantic web that can be used to find and get material on the e-learning domain.

\section{LITERATURE REVIEW}

Based on research [3] [4], the study [3] that discusses the application of semantic web to determine the choice of bus lines Trans Jogja, the steps being taken are divided into two, namely designing ontology and system design, the design of ontologies produce class among other classes TempatTujuan there property Listing BerangkatdariShelter, JalurYangDigunakan and ShelterTerdekat type object type. While the properties of the address, description, and rekomendasi_jalur nama_tujuan type datatype. Implementation of ontologies using protégé. The information search Trans Jogja bus lanes by leveraging ontology Trans
Jogja bus lines as a knowledge base can help the user to find relevant pathways.

Other studies related to the semantic web is also carried out by [5] building ontology model for flight information using protégé. By using protégé, a model of knowledge compiled in the form of flight schedules in a hierarchical ontology classes, slots and instant. Ontology model capable of describing information compiled more semantically flight schedule. And besides that, from the model that has been developed shows that the ways users (according to the perceptions of each) to search flight information or query results can be formed more easily.

Research conducted [6] apply to the domain of semantic web ontologies law to provide for the general user services easy and convenient to access information such as legal professionals.

From the results of studies and research above shows that the semantic web has been implemented widely in a variety of systems, and can be a solution for knowledge-based search.

\section{FUNDAMENTAL}

\subsection{Semantic Web}

The semantic web is a new generation of the web that already exist today, the semantic web is an evolution of the WWW (World Wide Web) coined by Tim Berners-Lee in 1999. With the semantic web, a web is not only understandable by humans (users) will but it can also be understood by a machine / computer (machine readable). The goal of the semantic web architecture is to provide knowledge representation of LOD (Linked of data) that allows the machine / computer processes on a global scale [4]. The semantic web is defined as a set of technologies, which allow a computer to understand the meaning of information based on metadata, ie information about the content of the information. With the metadata, the computer should be able to interpret the results of income information so search results to be more detailed and precise. W3C defines the metadata format is the Resource Description Framework (RDF). Each unit of RDF consists of three compositions, namely subject, predicate, and object. Subject and predicate is the entity indicated by the text, while the predicate is a composition that explains the viewpoint of the subject described object. The most attractive thing of RDF that object can be a subject that will be explained by any other object, so the object or entries can be explained clearly and in detail and in accordance with the wishes of users who provide input [1]. In general, the semantic web architecture can be seen in figure 1 . 


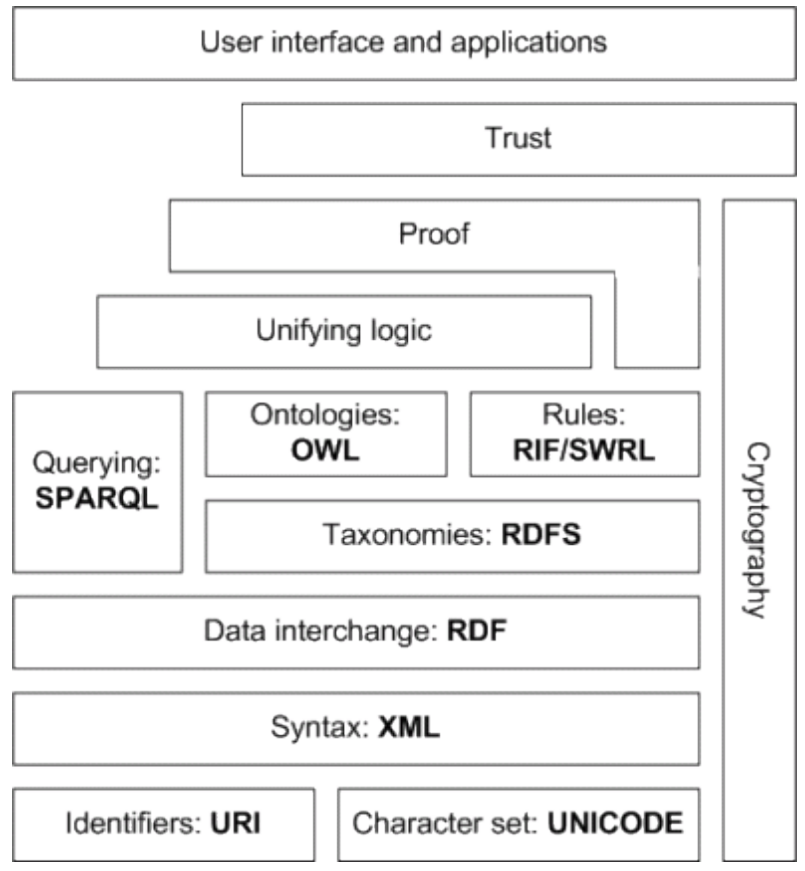

Figure 1. Architecture of Semantic Web

W3C call out semantic web architecture as the semantic web layer cake. $\mathrm{W} 3 \mathrm{C}$ recommends the semantic web activity, there are several layers of architecture of semantic web, among others [1]

1. URI/IRI, ensuring the use of a set of characters that have been agreed internationally and provides tools to identify objects in the semantic web.

2. Layer XML dan RDF, as a data interchange format

3. Layer $S P A R Q L$, is a query language at the same protocols used in accessing the data on the semantic web.

4. Layer RDF Schema dan $O W L$, is used to express the semantics of data and written in RDF format.

5. RIF (Rule Interchange Format), designed to address the problem of interoperability in the rule language used.

\subsection{Ontology}

Ontology is the key to the application of semantic web [7]. Ontologies can be defined as "an explicit specification of a conceptualization" [8]. Ontology is very important to describe something. Technically, ontology can be represented in the form of objects, properties of objects, and the relationships between each object [9]. Ontology languages represented using OWL (Web Ontology Language), OWL Initially designed to represent information about the category of an object and how that object relates. OWL can also provide information about the object itself. As a result of the work done by the W3C Semantic Web activity, OWL must be in accordance with the vision of the semantic web, the languages are grouped together with XML and RDF [1].

\subsection{RDF}

RDF (Resource Description Framework) is an application of XML that allows the construction of a resource-rich description, structured, and can be read by machine. RDF is a framework to describe a web page. Each document is a collection of RDF statements consisting of subject, predicate and object are commonly known as triples. This set of statements if it is described to form a set of nodes that are connected by a shaped edge direction of the arrow so as to form a graph. There are several famous RDF serialization formats including RDF / XML, Turtle (Terse RDF Triple Language) and N-Triples.

\subsection{SPARQL}

SPARQL (SPARQL Protocol and RDF Query Language) is a query language used to access documents RDF. SPARQL is similar to that of the relational SQL database. SPARQL makes it possible to do several things, namely, taking the value of structured data and data that is semi-structured, developing the data by performing queries against a relation that is not known, perform a query join operation complex on databases different in a more simple, and transform the data RDF into another vocabulary. SPARQL example can be seen in figure 2.

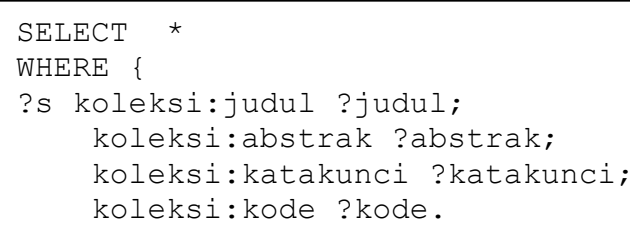

Figure 2. SPARQL Example

\section{RESEARCH METHODOLOGY}

In general, the stages in this study can be seen in Figure 3 .

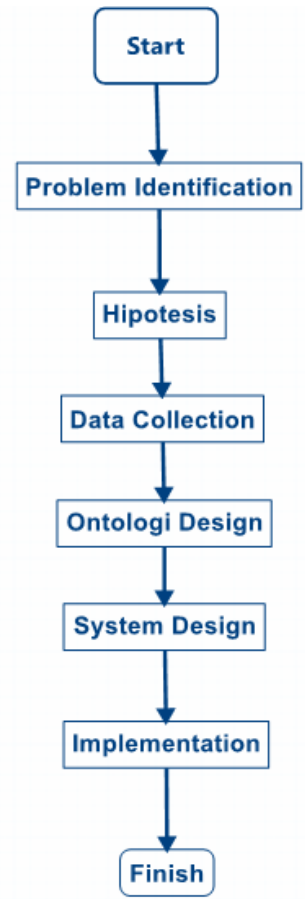

Figure 3. The research Steps

Figure 3 is a stage in conducting the study, the following explanation of these stages

1. Identify the problem, at this stage the identification of the issues involved, the problems that encourage research at the end of the study domain.

2. Hypothesis, this step determines the initial hypothesis that the semantic web can be applied to the learning resource domain to facilitate the search.

3. Data collection, data collection associated with learning resource domain. 
4. Design of Ontology, at this stage of the design ontology based on the results of data collection has been done.

5. System Design, at this stage of the system interface design.

6. Implementation, the next stage is to implement ontologies and semantic web interface design becomes.

The tools and materials used, among others:

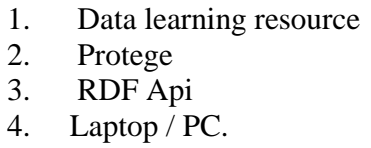

\section{RESULTS AND DISCUSSION}

\subsection{Design of ontology}

At this stage, ontology design, this design uses protégé. The results of the ontology design can be seen in Table 1, Table 2 and Table 3 .

Table 1. Class, SubClassOf

\begin{tabular}{|l|l|}
\hline Class & SubclassOf \\
\hline Jenis & Thing \\
\hline Kategori & Thing \\
\hline Lecturer & Thing \\
\hline Matakuliah & Thing \\
\hline Materi & Thing \\
\hline
\end{tabular}

Table 2. Object property

\begin{tabular}{|c|c|c|}
\hline Object Property & Domain & Rannge \\
\hline Create & lecture & materi \\
\hline HasAuthor & materi & lecture \\
\hline HasJenis & materi & jenis \\
\hline HasKategori & materi & kategori \\
\hline HasMateri & matakuliah & materi \\
\hline Teach & lecturer & matakuliah \\
\hline
\end{tabular}

Table 3. Data Property, Domain dan Range

\begin{tabular}{|l|l|l|}
\hline Data Property & Domain & Range/Value \\
\hline hasBirthdate & Lecturer & Date \\
\hline hasKodeMatkul & Matakuliah & String \\
\hline hasNamaFile & Materi & String \\
\hline hasNamaJenis & Jenis & String \\
\hline hasNamaKategori & Kategori & String \\
\hline hasNamaMatkul & Matakuliah & String \\
\hline hasName & Lecturer & String \\
\hline
\end{tabular}

\begin{tabular}{|l|l|l|}
\hline hasNidn & Lecturer & String \\
\hline hasSex & Lecturer & String \\
\hline hasSKS & Matakuliah & String \\
\hline hasTipeDokumen & Materi & String \\
\hline hasTitle & Materi & String \\
\hline hasURL & Materi & String \\
\hline
\end{tabular}

\subsection{Design of semantic web user interface} At the design step of this semantic web interface (Figure 4).

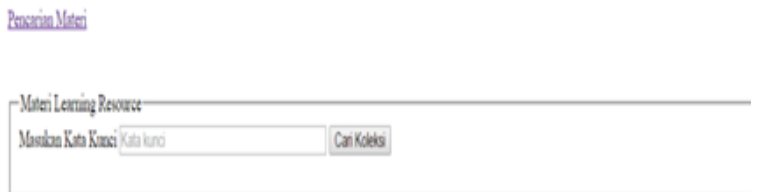

Figure 4. User interface

\subsection{Implementation of ontology}

After designing ontology in step 5.1, the next step is the implementation of the concept ontology using protégé.

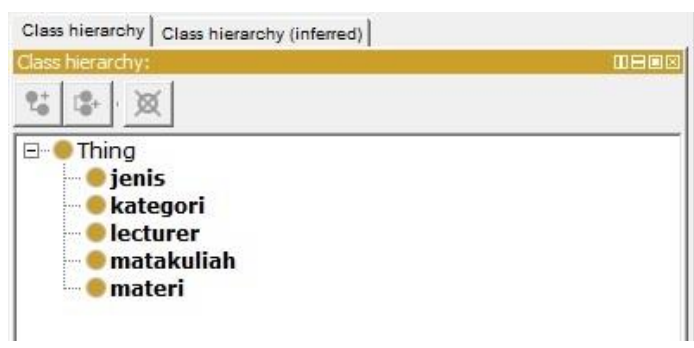

Figure 5. Implementation of ontology

A In designing the ontology generated five classes:
1. Class Type
2. Class Category
3. Class Lecturer
4. Class Course
5. Class Materials

While the implementation of ObjectProperty produced can be seen in Figure 5

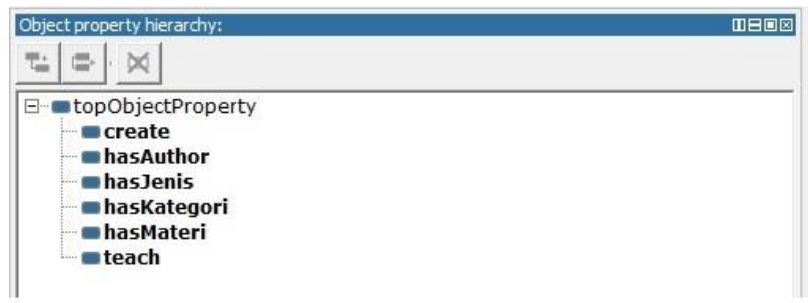

Gambar 6. Implementation of Object Property 
1. create, in which this property has a lecture and Ranges domain material

2. hasAuthhor, have a material domain with lecturer ranges.

3. hasJenis, with the material domain and ranges type.

4. hasMateri, with domain and subject matter ranges.

5. teach, with the lecturer and ranges domain material..

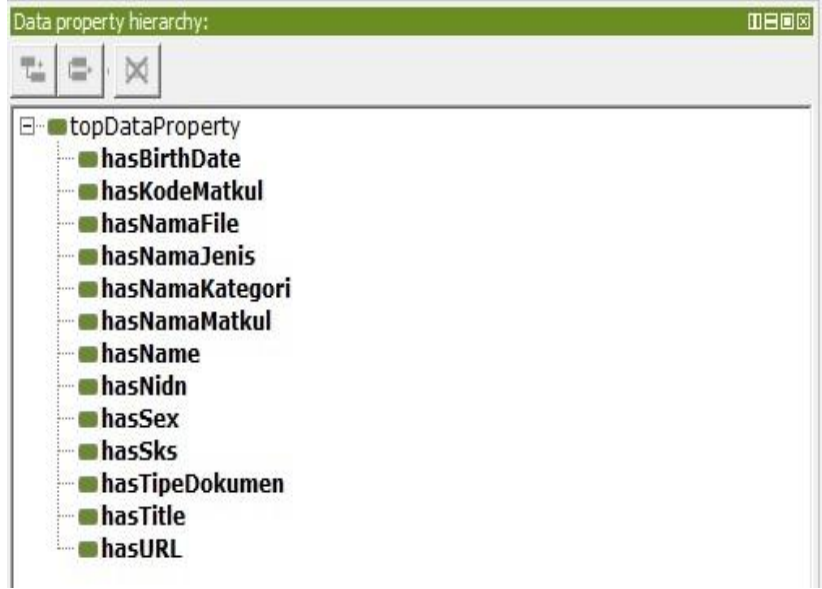

Gambar 7. Implementasi Data Property

An overview of the implementation of the ontology can be seen in Figure 8

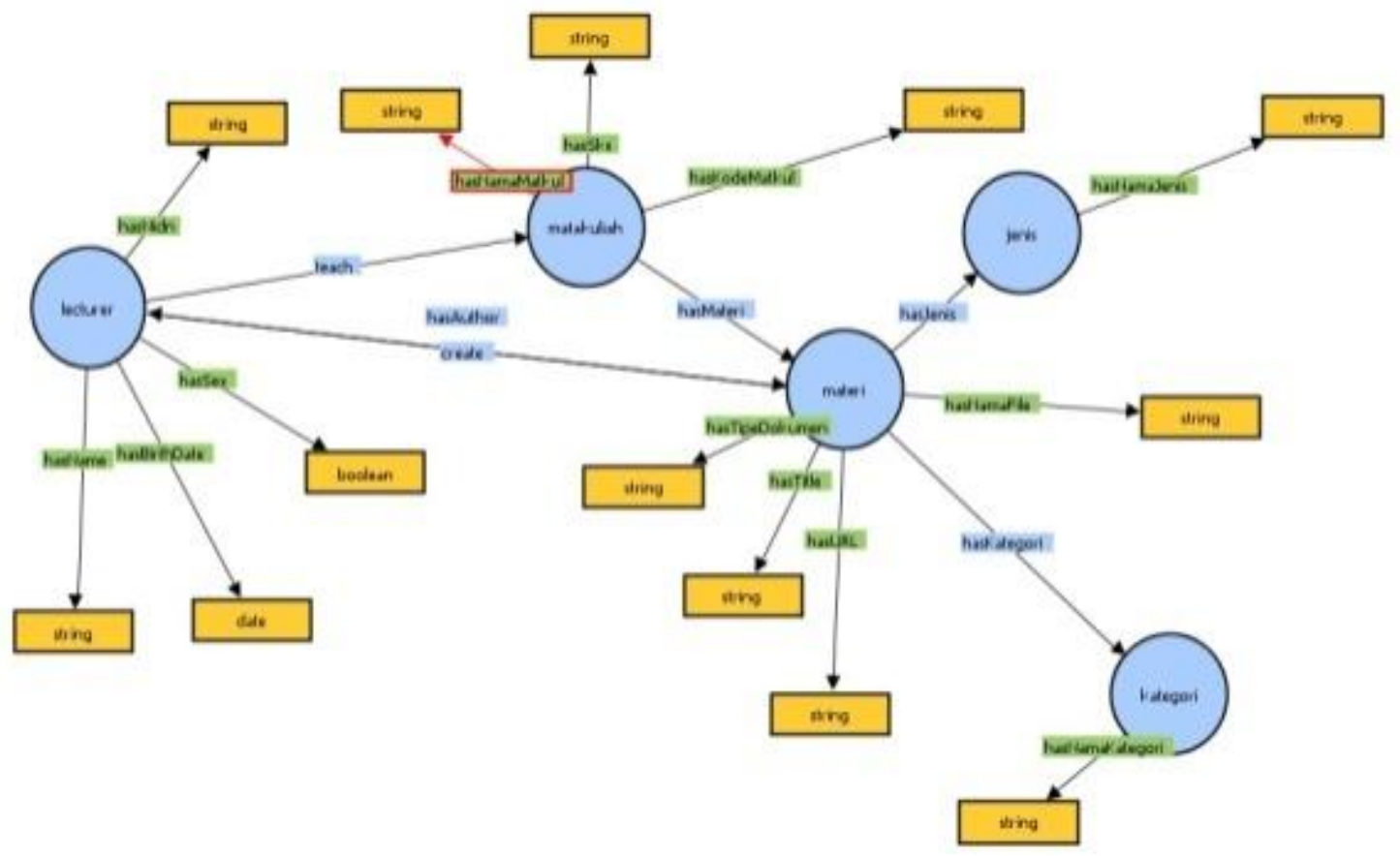

Figure 8. Ontology VOWL

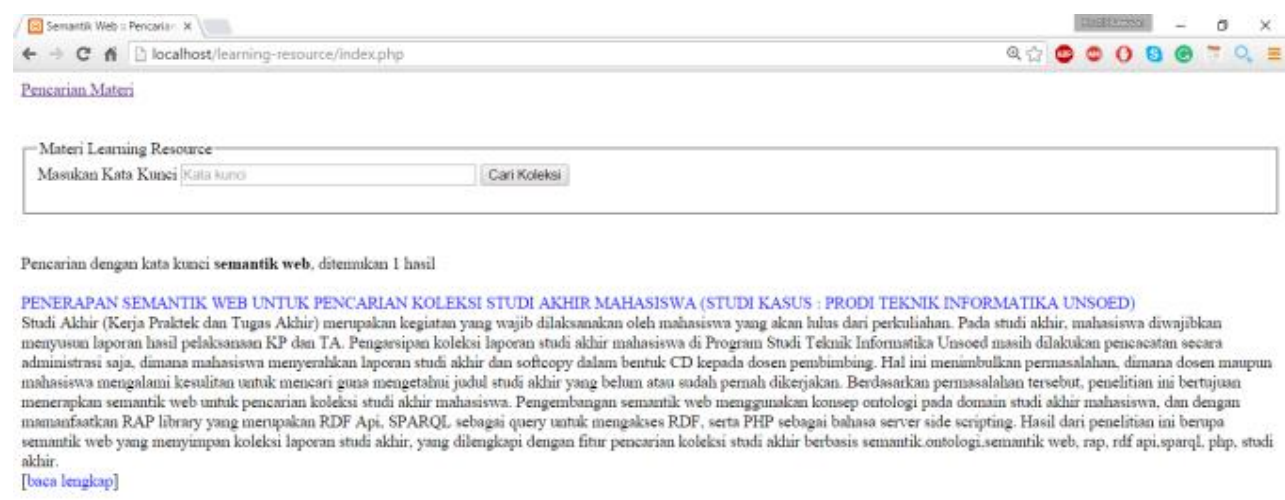




\section{CONCLUSION}

Results from the study showed that semantic web technologies can be implemented as an application for a search on the domain of learning resources. For the next development need to apply SWRL (semantic web rule language), so that the application is able to perform inference. The addition of more data can be carried out to determine the measurement results further applications.

\section{REFERENCES}

[1] H. F. Gunawan, "Penerapan Web Semantik Untuk Aplikasi Pencarian Pada Repositori Koleksi Penelitian ,Studi Kasus: Program Studi Sistem Informasi Stmik Mikroskil Medan," JSM STMIK Mikroskil, vol. 15, no. 1, pp. 51-60, 2014.

[2] N. S. Salahuddin and H. Muchpud, "PEMBUATAN ONTOLOGY LEARNING OBJECT PADA," Konf. Nas. Sist. Inf., pp. 282-286, 2012.

[3] I. A. S. Wicaksono, N. Charibaldi, and H. Jayadianti, "Penerapan Teknologi Semantic Web untuk Menentukan Pilihan Jalur Bis Trans Jogja,” Semin. Nas. Inform. 2010
(semnasIF 2010), vol. 2010, no. semnasIF, pp. 102-110, 2010 .

[4] K. I. Lakhtaria and M. Trivedi, "Providing Smart-Space to E-Commerce with Semantic Web," vol. 1, no. 1, pp. 27-34, 2011.

[5] Azhari Azhari and Minurita Sholichah, "Model Ontologi Untuk Informasi Jadwal Penerbangan Menggunakan Protégé," J. Inform., vol. 7, no. 1, pp. 67-76, 2006.

[6] D. W. Jo, "Web-based Semantic Web Retrieval Service for Law Ontology," 2013.

[7] A. Gali, C. X. Chen, K. T. Claypool, and R. Uceda-sosa, "From Ontology to Relational Databases," pp. 1-12.

[8] T. R. Gruber, "A translation approach to portable ontology specifications," Knowl. Acquis., vol. 5, no. 2, pp. 199-220, 1993.

[9] B. Chandrasekaran, J. R. Josephson, and V. R. Benjamins, "What Are Ontologies , and Why Do We Need Them ?," 1999. 